http://jmscr.igmpublication.org/home/ ISSN (e)-2347-176x ISSN (p) 2455-0450

crossref DOI: https://dx.doi.org/10.18535/jmscr/v9i10.07

\title{
Prevalence of audiological impairment in children with cleft palate
}

\author{
Authors \\ Neelikattu Aathira Tess Thomas, Supriya Patil*, Neha Deshmukh \\ *Corresponding Author \\ Supriya Patil
}

\begin{abstract}
Incidence of cleft palate is the commonest anomaly in the orofacial region. Although much progress has been made in the field of cleft palate, middle ear problems and hearing loss is highly prevalent in children with cleft palate.

Methods: An observational study including 30 children with cleft palate who attended the ENT OPD of MGM Hospital from Jan 2018-Feb 2019, between the age group of lyear to 6 years.

Results: In our study, Otitis Media with Effusion (OME) was seen in 50\% of the children with cleft palate. Tympanogram of B type suggesting OME was observed in $60 \%$ of cases.

Conclusion: Otological and audiometric assessment should be performed for all patients having cleft palate before surgery for early identification and intervention for middle ear problems particularly middle ear effusion.
\end{abstract}

\section{Introduction}

Clefts of the lip, alveolus and palate constitute amongst the most common congenital malformations of the head and neck and the second most common of all congenital malformations in general. ${ }^{(1)}$ It occurs when tissues in the face and mouth do not fuse properly by the 2nd or 3rd month of pregnancy. ${ }^{(2)}$

Cleft lip and palate are a group of congenital anomalies that put emotional, physical and monitory stress over the child and well as the patient's family member. Children born with this anomaly have to undergo a number of corrective surgeries and get repeated treatment for the accompanying complications as well.

Children with cleft palate have been reported to have higher chances of developing otitis media. ${ }^{(3,4)}$ The etiology has been attributed to
Eustachian tube dysfunction caused by failure of palatal muscle function leading to secondary obstruction of fluid. ${ }^{(5)}$

At least one episode of otitis media by the age of three years is observed in seventy-one percent of all children. ${ }^{(5)}$ Recurrent episodes of acute otits media or otitis media with effusion have been reported in kids with cleft palate. ${ }^{(6)}$ In a study by Dhillon a $97 \%$ incidence of otitis media with effusion were observed in children with cleft palate in less than 24 months of age. ${ }^{(7)}$

In children with cleft palate, greater importance is paid to the correction of the deformity which in turn leads to little or no focus on the hearing of the child which plays an important role in the developmental and cognitive function in later life. Early detection of audiological impairment and appropriate management is vital in children with 
cleft palate. The following study is undertaken to evaluate the prevalence of audiological impairment in children with cleft palate.

\section{Materials and Methods}

A observational study including 30 children with cleft palate who attended the ENT OPD of MGM Hospital from Jan 2018-Feb 2019 (ranging from the age group of 1 year to 6 years). Data was collected after obtaining written consent of parent/guardian. Detailed History of each child was taken from the accompanying parent/ guardian. They each underwent standard clinical, ontological examination. Impedance audiometry was done by an experienced audiologist.

Inclusion Criteria: Children from the age of 1year to 6 years with cleft palate.

Exclusion Criteria: Operated case of cleft palate. Children with any other congenital or craniofacial anomaly

Ethical Issues: Permission was taken from the institutional ethical committee. Written and valid consent was taken from the parent/guardian as the case subjects were children

\section{Role of Middle Ear Anatomy}

The middle ear cavity extends from the tympanic membrane to the inner ear. It's volume is approximately two cubic centimeters The middle ear cavity connects with the nasopharynx through the Eustachian tube.

\section{Eustachian Tube}

The Eustachian tube help in pressure equalization and ventilation of the middle ear. There is optimal transmission of sound through the eardrum when the air pressure is equal between the outer and middle ear. When the air pressure is unequal, the eardrum is forced outward or inward which cause discomfort and reduction in the transmission sound.

\section{Muscles}

The tensor velipalatini tendon is the only muscle which helps in opening the eustachian tube, which in turn leads to ventilation and drainage of the middle ear. This explains the pathology of middle ear diseases in children with cleft palate.

\section{Results}

Of the 30 children examined, 20(90\%) were males while only $10(10 \%)$ were females. Amongst 30 children of cleft palate, unilateral cleft palate was noted in $23(76.6 \%)$ children, bilateral were observed in $6(20 \%)$ and only $1(3.33 \%)$ child showed submucous cleft palate.

Otoscopic examination showed retraction of the pars tensa in $6(20 \%)$ patients which was indicative of past or present possible middle ear dysfunction. Also observed in 30 children, $15(50 \%)$ children had findings of OME, 6(20\%) had findings of chronic otitis media out of which $2(33.33 \%)$ had squamosal type and $4(66.67 \%)$ had mucosal type and the remaining $9(30 \%)$ had normal tympanic membrane.

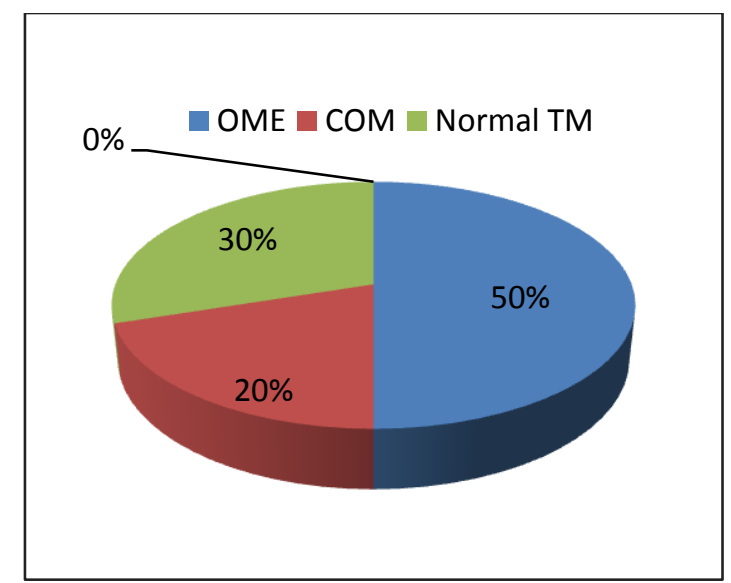

Fig 1: Pie chart depicting Otoscopic findings.

Tympanometry which is an objective test was done by an experienced audiologist, 18(60\%) had Type B tympanogram curve which was common type and in accordance with the clinical findings. $6(20 \%)$ children had the Type A tympanogram which was the $2^{\text {nd }}$ commonest, As type was seen only in $1(3.33 \%)$ ear and D type in $5(16.66 \%)$ ears. 


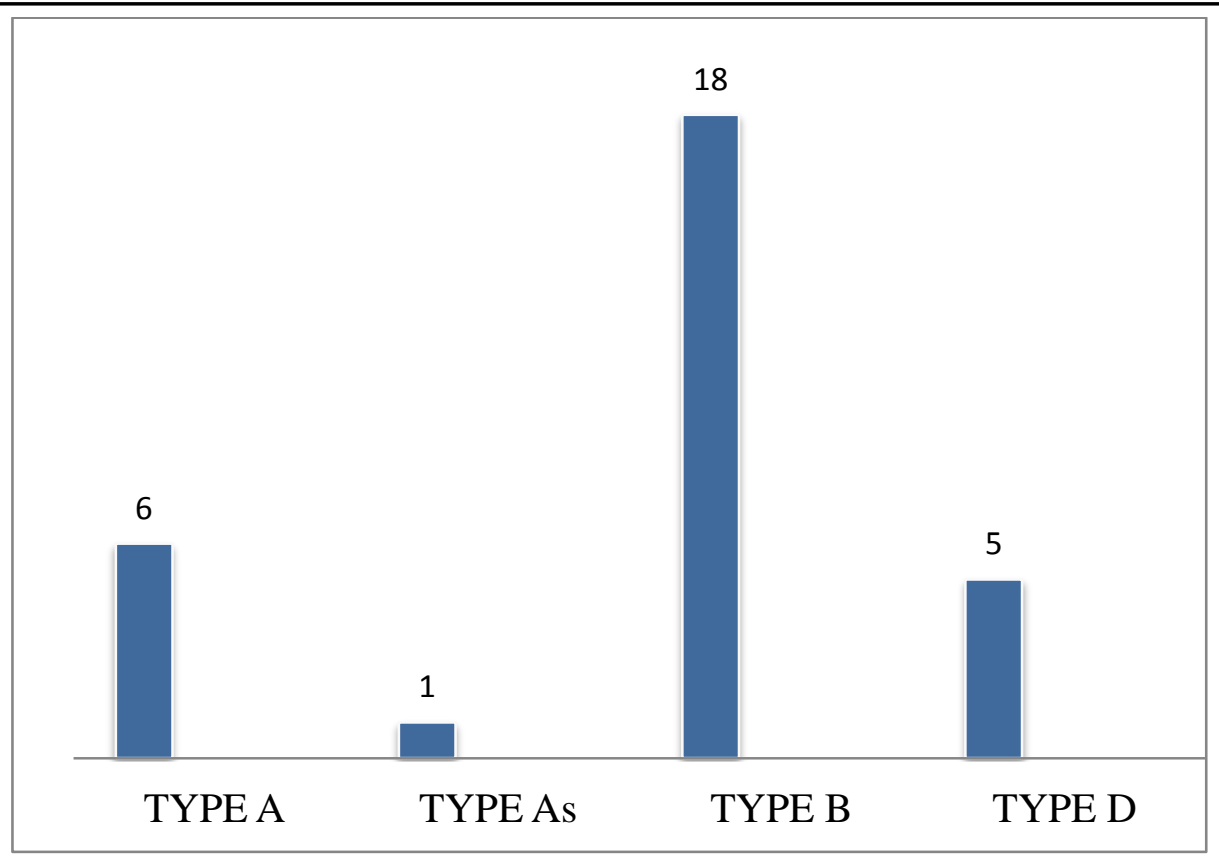

Fig 2: Graph showing Otoacoustic emission distribution.

\section{Discussion}

Clefts of the orofacial region are the commonest congenital anomaly of the craniofacial region. Around 27,000 to 33,000 per year of live births were reported to have clefts. ${ }^{(3,4)}$ The risk of middle ear disorders and hearing loss is $50 \%-90 \%$ in children with cleft palate as is confirmed by many studies. ${ }^{(7-9)}$ The inability of the palatal muscles to open the eustachian tube results in the middle ear and hearing disorders in these children. ${ }^{(10)}$

A male to female ratio of 2:1 have been observed in many studies in children with cleft palate. ${ }^{(11)}$ Similar results were observed in this study too with the male to female ratio of $2: 1$

Around 6(20\%) of the cases examined had otoscopic finding of retracted pars tensa suggestive of possible otitis media in the past. This is similar to study reports done in India. ${ }^{(12,13)}$

In this study out of 30 children, 19 had past history of ear problems noted mainly by the parents, while only 3 children had sort medical treatment for hearing related complaints. Many reports have commented on varying degrees of hearing loss noted in children with cleft palate. $^{(14,15)}$

Otoscopically, a prevalence of $15(50 \%)$ of OME was seen in this study which was the commonest finding, 6(20\%) were suggestive of chronic otitis media the remaining $9(30 \%)$ had normal ear findings. This is similar to the study conducted by Zingade $^{(11)}$ which showed prevalence of OME to be $55.2 \%$.

Impedance audiometry done of all 30 children in this study showed, 18(60\%)children having Type B tympanogram which was the commonest, followed by 6(20\%) having Type A tympanogram and $5(16.66 \%)$ with Type D. These finding were similar to study conducted by Zingade ${ }^{(11)}$ whereas in a study done by Subramaniam $\mathrm{V}$ et $\mathrm{al}^{(16)}$ majority of case and control showed Type A tympanogram.

As majority of patients had finding suggestive of OME, early intervention is recommended, hearing loss in childhood could affect speech and language development as well as performance at school and later life.

\section{Conclusion}

A larger sample size is needed to further analyze middle ear problems in children with cleft palate. Based on our observations and audiological findings of this study, a detailed ENT examination and necessary audiological testing is of primary importance prior to planning the child for cleft palate repair.It would enable prevent progression 
of hearing loss in these patients as well as minimize complications.

\section{References}

1. Shaye D, Liu CC, Tollefson TT. Cleft Lip and Palate: an evidence-based review. Facial Plast Surg Clin North Am. 2015;23(3):357-72.

2. Garcia-Vaquero et al. Otologic, audiometric and speech findings in patients undergoing surgery for cleft palate. BMC Pediatrics (2018) 18:350.

3. Mossey P, Little J. Addressing the challenges of cleft lip and palate research in India. Indian J Plast Surg. 2009;42(suppl):9-18.

4. IPDTOC Working Group. Prevalence at birth of cleft lip with or without cleft palate: data from the International Perinatal Database of Typical Oral Clefts (IPDTOC). Cleft Palate Craniofac J. 2011 Jan;48(1):66-81.

5. Teele DW, Klein JO, Chase G, Menyuk P, Rosner BA; Greater Boston Otitis Media Study Group. Otitis media in infancy and intellectual ability, school achievement, speech, and language at age 7 years. J Infect Dis. 1990;162:685-94.

6. Stool SE, Randall P. Unexpected ear disease in inafants with cleft palate. Cleft Palate J. 1967;4:99-103.

7. Dhillon RS. The middle ear in cleft palate children, pre and post palatal closure. $J R$ Soc Med. 1988;81:710-3.

8. Paradise JL, Smith CG, Bluestone CD. Tympanometric detection of middle ear effusion in infants and young children. Pediatrics. 1976;58:198- 210.

9. Broen PA, Moller KT, Karlstorm J, Doyle SS, Devers M, Keenan KM. Comparison of hearing histories of children with and without cleft palate. Cleft Palate Craniofac J. 1996;33:127-33.
10. Bluestone CD, Wittel RA, Paradise JL. Roentgenographic evaluation of Eustachian tube function in infants with cleft and normal palates. Cleft Palate J. 1972;9:93-100.

11. Zingade ND, Sanji RR. The prevalence of otological manifestations in children with cleft palate. Indian J Otolaryngol Head Neck Surg. 2009;61(3):218-22.

12. Robinson PJ, Lodge H, Jones PM, Walker CC, Grant HR. The effect of cleft palate repair on otitis media with effusion. PlastReconstr Surg. 1992;89:640-5.

13. Penfold C, Cleft L, Palate. Cleft lip and palate. In: Gleeson M, Browning GG, Burton MJ, Clarke R, Hibbert J, Jones NS, et al., eds. Scott Brown's Otolaryngology, Head and Neck Surgery. 7th ed. Great Britain: Hodder Arnold; 2008: 996-1018.

14. 14.Khan SY, Pal R, Sengupta A, Roy P (2006) Clinical study of otological manifestations in cases of cleft palate. IJOHNS 58:35-37.

15. Too-Chung MA (1983) The assessment of middle ear function and hearing by tympanometry in children before and after early cleft palate repair. Br J PlastSurg 36:295-299.

16. Subramaniam V et al. Otological and audiological manifestations in cleft lip and cleft palate children: a clinical study. Int J Otorhinolaryngol Head Neck Surg. 2015 Jul;1(1):7-10. 